\title{
DOCUMENTAR LA EXPERIENCIA BIOGRÁFICA Y PEDAGÓGICA. LA INVESTIGACIÓN NARRATIVA Y (AUTO)BIOGRÁFICA EN EDUCACIÓN EN ARGENTINA
}

DANIEL HUGO SUÁREZ

Universidad de Buenos Aires

PAULA VALERIA DÁVILA

Universidad de Buenos Aires

RESUMEN En este artículo nos proponemos realizar un aporte para el trazado provisorio de una suerte de cartografía que dé cuenta de los grupos de investigación y del estado de los debates que tienen lugar en Argentina en relación con el campo biográfico-narrativo en educación. Aunque sería imposible hacerlo de modo exhaustivo, nuestra intención es presentar un esbozo de contenidos y temas que abordan esos grupos y los espacios que han venido generando para que el encuentro y la conversación entre ellos tengan lugar. Al mismo tiempo, nos interesa discutir sus efectos para la construcción de saberes y conocimientos acerca de la experiencia biográfica de docentes y educadores en diferentes contextos educativos en su cruce con la investigación, la formación y la acción pedagógicas. El intento de esta labor cobra sentido frente a dos hipótesis de trabajo en tensión: a) el campo biográfico-narrativo en educación en nuestro país se ha mostrado como fértil para el pensamiento y la acción pedagógicos, sin embargo b) el número de grupos de investigación educativa que se han aventurado a experimentar epistemológicamente en él es aún acotado.

Palabras clave: Investigación educativa. Investigación (auto)biográfico-narrativa. Formación docente.

\section{ABSTRACT DOCUMENT THE BIOGRAPHICAL AND PEDAGOGICAL EXPERIENCE. NARRATIVE AND (AUTO) BIOGRAPHICAL RESEARCH IN EDUCATION IN ARGENTINA}

In this article we propose to make a contribution for the provisional mapping of a kind of cartography that accounts for the research groups and the state of the debates that take place in Argentina in 
relation to the biographical-narrative field in education. Although it would be impossible to do it in an exhaustive way, our intention is to present an outline of contents and topics that address those groups and the spaces they have been generating so that the meeting and the conversation between them take place. At the same time, we are interested in discussing its effects for the construction of knowledge about the biographical experience of teachers and educators in different educational contexts in their intersection with research, training and pedagogical action. The attempt of this work makes sense around of two working hypotheses in tension: a) the biographical-narrative field in education in our country has been shown as fertile for pedagogical thought and action, however $b$ ) the number of groups of Educational research that they have ventured to experience epistemologically in it is still bounded.

Keywords: Educational research. (Auto)biographical-narrative research. Teacher training.

\section{RESUMO DOCUMENTAÇÃO DA EXPERIÊNCIA BIOGRÁFICA E PEDAGÓGICA. PESQUISA NARRATIVA E (AUTO) BIOGRÁFICA EM EDUCAÇÃO NA ARGENTINA}

Neste artigo, nos propomos a fazer uma contribuição para um levantamento provisório do estado da arte dos grupos de pesquisa e das discussões que estão ocorrendo na Argentina, em relação ao campo biográfico-narrativo em educação. A nossa intenção é apresentar um esboço do conteúdo e temas que abordam esses grupos e espaços. Ao mesmo tempo, queremos discutir seus efeitos para a construção de conhecimento sobre a experiência biográfica de professores e educadores, em diferentes contextos educacionais, em sua interseção com a investigação, a formação e a ação pedagógica. A intenção deste trabalho ganha relevância a partir de duas hipóteses em tensão: a) o campo biográfico-narrativo em educação no nosso país tem se mostrado fértil para o pensamento e de ação pedagógica, no entanto b) o número de grupos de pesquisa educacional que se aventuraram a experimentar epistemologicamente tal campo ainda é limitado.

Palavras-chave: Pesquisa educacional. Pesquisa (auto)biográficanarrativa. Formação de professores. 
En este artículo nos proponemos realizar un aporte para el trazado provisorio de una suerte de cartografía que dé cuenta de los grupos de investigación y del estado de los debates que tienen lugar en Argentina en relación con el campo biográfico-narrativo en educación. Aunque sería imposible hacerlo de modo completo y exhaustivo, nuestra intención es presentar los temas y cuestiones que abordan esos grupos y algunos de los espacios que han venido generando para que el encuentro y la conversación entre ellos tengan lugar. Al mismo tiempo, nos interesa dar cuenta de sus efectos para la construcción de saberes y conocimientos acerca de la experiencia biográfica de docentes y educadores en diferentes contextos del territorio educativo en su cruce con la investigación, la formación y la acción pedagógicas. Por supuesto, el mapa que resulte de este esfuerzo solo será un esbozo, un nuevo dibujo imperfecto y en construcción, una notación provisoria de acontecimientos, grupos y temas, porque nuestra perspectiva está inevitablemente sesgada por nuestra participación y compromiso en el campo. También por nuestra trayectoria, vinculaciones y localizaciones en él. Tal vez este ejercicio cartográfico sea una oportunidad para producir una interrupción, reflexionar sobre estos movimientos y posicionar actores, experiencias y saberes de un territorio en expansión.

El intento de mapear el territorio cobra sentido, además, frente a dos hipótesis de trabajo en tensión: a) el campo biográfico-narrativo en educación en nuestro país se ha mostrado "como un suelo fértil para el pensamiento y la acción pedagógicos" (SUÁREZ, 2014, p.764); sin embrago, b) el número de grupos de investigación educativa que se han aventurado a experimentar epistemológicamente en él es todavía acotado, y son pocos investigadores que se referencian explícitamente como afiliados a esa tradición. Aun cuando en la Argentina hay un uso extendido y cada vez más creciente de las narrativas como fuentes de la investigación cualitativa, en el campo educativo éste ha venido de la mano de enfoques adscriptos a los diversos subcampos disciplinarios y reglas metodológicas de las ciencias de la educación (sociología de la educación, antropología de la educación, historia de la educación, etc.), que han primado a la hora de definir programas y proyectos de investigación, tesis y otros estudios académicos.

\section{Investigaciones educativas que usan narrativas y (auto)biografias}

Se puede afirmar que en las universidades públicas de Argentina la mayor parte de la investigación en educación es cualitativa. Y, además, que una buena parte de ella se pretende etnográfica, histórica o sociológica, más que pedagógica y/o (auto)biográfica y narrativa. Dentro de los marcos metodológicos y comunidades de referencia de esas perspectivas, provenientes no sólo del campo pedagógico sino de las diversas disciplinas científicas que estudian a la educación, innumerables investigadores generan, sistematizan y analizan/interpretan corpus narrativos como fuentes para la descripción y la compresión de las significaciones puestas a jugar por los sujetos de las prácticas. Las historias de vida, las historias orales, los memoriales, las historias profesionales, los relatos de experiencia, las novelas de formación, las narraciones de sí, en general, se expanden cada vez más en los estudios cualitativos de la educación y son utilizadas recurrentemente por los investigadores educativos como recursos metodológicos. Sus trabajos investigativos son desarrollados, por ejemplo, en un marco de interrogación etnográfica, como es el caso de Graciela Batallán (2007) o de investigadoras que conjugan la narración con la formación docente desde una mirada etnográfica de 
las prácticas (HERMIDA, PIONETTI Y SEGRETIN, 2017).

Por su lado, otras estrategias de investigación cualitativa también recurren a las narrativas para explorar e indagar distintos territorios educativos. Sólo por tomar algunos ejemplos que vienen desplegándose en el último tiempo en Argentina, podemos mencionar algunos proyectos de investigación que viene dirigiendo Sandra Carli desde hace casi una década en el Instituto Investigaciones Gino Germani de la Universidad de Buenos Aires ${ }^{1}$ en torno de la universidad pública; más específicamente, de la experiencia universitaria. En sus inicios estas investigaciones versaron sobre la experiencia estudiantil y en los últimos años sobre las biografias de profesores y profesoras de ciencias sociales y humanas, en tanto uno de los actores claves en la modulación de la cultura institucional. Según esta investigadora, la pregunta por la experiencia universitaria abrió un campo fértil de indagaciones, pues permitió explorar la vida universitaria desde una nueva perspectiva. Los relatos biográficos de estudiantes al mismo tiempo que daban forma a una visión sobre la experiencia transcurrida desde el ingreso hasta la graduación, en un ciclo histórico y en un contexto de crisis social generalizada, ofrecían una mirada compleja sobre las instituciones, tanto desde una perspectiva sociocultural como histórica. La investigación sobre la experiencia estudiantil puso en primer plano los avatares cotidianos de los procesos de producción, transmisión y apropiación del conocimiento y ello generó en los últimos años la incursión de este equipo de in-

1 Se trata de los proyectos “La universidad pública en perspectiva histórica: culturas institucionales, biografias de profesores/as y experiencias de conocimiento" (Programación UBACyT 2014-2017) y "Transformaciones de los procesos de adquisición, producción y transmisión de conocimiento universitario. Un estudio centrado en las historias de vida de profesores/ as de la Universidad de Buenos Aires del área de humanidades y ciencias sociales" (Proyecto PIP-CONICET 2011-2014/UBA. IIGG). vestigación en las experiencias de profesores y profesoras, en la reconstrucción de biografías académicas de una generación que viene teniendo un papel decisivo en la configuración de las humanidades y las ciencias sociales. Para Carli, los enfoques biográficos permiten ahondar en el papel que los sujetos individuales y colectivos han tenido en la emergencia, desarrollo e institucionalización de áreas de conocimiento, bajo el telón de fondo en la Argentina de instituciones signadas por procesos de crisis e inestabilidad permanentes.

En articulación con este equipo de investigación, desde el Instituto Rosario de Investigaciones en Ciencias de la Educación (IRICE-CONICET-UNR), María Paula Pierella (2015a) viene trabajando en las relaciones entre universidad, conocimiento y transmisión a través de estudios centrados en biografias de profesores de carreras humanísticas y científicas como modo de explorar los saberes necesarios y las experiencias de formación, y en particular, ha indagado cómo es la enseñanza en los primeros años de la universidad desde una aproximación biográfico-narrativa a los relatos de profesores de la Universidad Nacional de Rosario (PIERELLA, 2015b)2.

También otras investigadoras han recurrido a la utilización de las narrativas como recurso metodológico en la investigación cualitativa en educación desde el Instituto de Investigaciones en Ciencias de la Educación de la Facultad de Filosofía y Letras de la Universidad de Buenos Aires. Tal es el caso de Sandra Llosa, que apela a las historias de vida como herramienta forjada desde la tradición francófona de Gaston Pineau, Daniel Bertaux, Marie-Christine Jossó, Pierre Dominicé y del ita-

2 Por otra parte, también se ha interesado por aproximarse a las nociones de autoridad a través de las narrativas de estudiantes universitarios (PIERELLA, 2010) y ha llegado a problematizar la universidad pública como espacio de experiencias culturales por medio de itinerarios biográficos de jóvenes estudiantes (PIERELLA, 2012). 
liano Franco Ferraroti. En sus estudios destaca el entramado de experiencia, memoria y formación que tiene lugar a través del trabajo con biografias educativas y para ello refiere a los antecedentes en el campo de la educación de adultos, que ha desarrollado esta perspectiva epistemológica y metodológica de investigación - formación - transformación en torno a las biografias educativas (LLOSA, 2004). Como un rasgo peculiar y sumamente interesante, en el marco de un proyecto de investigación que Sandra Llosa codirigió junto a María Teresa Sirvent, se han analizado las experiencias educativas de personas adultas recogidas en el ejercicio de la memoria puesta en juego en la reconstrucción de sus biografias educativas desde un abordaje cualitativo que las combina con instancias participativas (LLOSA, 2016)33.

\section{Investigaciones narrativas y (auto)biográficas en el campo de la pedagogía}

Cabe aclarar que estas y otras investigaciones del campo educativo en Argentina (que no nos es posible reseñar aquí por razones de espacio) acuden a las narrativas como herramienta -una más entre otras- de recolección de datos, o como fuente o material de análisis e interpretaciones. Sólo una pequeña porción de investigadores educativos de las universidades argentinas nos inscribimos deliberadamente en la tradición de la investigación (auto)biográfica y narrativa con la firme intención de conformar un colectivo que, desde el espacio académico, se estructure en torno de ella y

3 Las conclusiones arrojadas refieren a que las demandas educativas presentan un devenir histórico-biográfico de construcción, a través de la sucesión de marcos vitales a lo largo de toda la vida y en una interrelación compleja donde el procesamiento psicosocial de aspectos y condiciones que hacen a las experiencias educativas previas impacta sobre las decisiones presentes y sobre la proyección de la propia formación a futuro. desenvuelva sus potencialidades y problematice sus alcances como un enfoque peculiar de investigación pedagógica. Y sólo en los últimos tiempos estos grupos de investigadores hemos logrado cierta visibilidad y cierta legitimidad en el debate público y especializado de la investigación en las ciencias de la educación desde un enfoque explícitamente (auto)biográfico y narrativo (SUÁREZ, 2014). Aunque con estrategias y contenidos diversos, nuestro aporte original ha sido la expansión de modalidades de investigación narrativa y (auto)biográfica en el campo pedagógico, escolar y académico, que se orientan a interrogar, comprender e interpretar la experiencia educativa, los procesos de formación de las subjetividades, particularmente las de los docentes y estudiantes, y algunos aspectos de las relaciones pedagógicas que hacen posible la transmisión cultural.

Podemos afirmar que la diversidad creciente de estos estudios significó una revitalización de la imaginación pedagógica en el campo educativo y un viraje en las formas de nombrar, pensar y narrar la educación (SUÁREZ, 2014). En este estudio trataremos de dar cuenta de esa pluralidad, pero nos detendremos en describir los desarrollos que intentan combinar la investigación narrativa y (auto)biográfica del mundo escolar mediante estrategias de colaboración o co-participación entre investigadores y educadores, la formación y el desarrollo profesional de los participantes, y la elaboración de propuestas de intervención pedagógica informadas en el conocimiento (co)producido y en las capacidades profesionales y pedagógicas fortalecidas.

En primer lugar, cabe mencionar los proyectos de investigación que desde el año 2004 viene dirigiendo Andrea Alliaud en el Instituto de Investigaciones en Ciencias de la Educación de la Facultad de Filosofía de la Universidad de Buenos Aires. Se trata de los Proyectos "El saber de la experiencia: experiencias peda- 
gógicas y subjetividad en la trayectoria profesional de los docentes" (UBACYT 2004-2007) y "Pedagogos, docentes y relatos de experiencia. Saberes pedagógicos y experiencias formativas durante la trayectoria profesional" (UBACYT 2008-2011) ${ }^{4}$, con la co-dirección de Daniel Suárez; "Dimensiones del saber profesional docente. Su estudio y aportes a la formación" (UBACyT 2011-2014)5 y “Formación docente: modelos, estructuras, trayectorias y prácticas en el marco de la preparación profesional" (UBACyT 2014-2017) ${ }^{6}$, con la co-dirección de Lea Vezub.

4 Este proyecto se propuso comprender e interpretar algunas dimensiones vinculadas con la construcción social del saber pedagógico y contribuir al debate especializado sobre la formación docente. Por un lado, interesó mostrar cómo los textos de algunos pedagogos modernos enriquecieron el lenguaje especializado y público de la pedagogía y cómo esos autores usaron determinadas estrategias discursivas que influyeron en la práctica de enseñar. Por otro lado, la investigación pretendió analizar las prácticas y estrategias discursivas que ponen en juego los docentes cuando documentan narrativamente sus experiencias, así como los contenidos y núcleos significativos del saber pedagógico que construyen a través de sus relatos. Complementariamente, la investigación avanzó en el conocimiento acerca de la naturaleza de las experiencias formativas y saberes pedagógicos elaborados por los docentes a lo largo de su trayectoria profesional, las formas de saber relativas a la tarea de enseñar y las maneras en que se vinculan con contextos y situaciones determinadas.

5 Este proyecto tuvo como objetivo indagar, por una parte, los saberes profesionales tal como estos son construidos y movilizados en situaciones de trabajo y; por otra parte, analizar los procesos de categorización y sistematización de esos saberes que ha realizado la investigación académica. Se abordaron diferentes dimensiones que configuran el saber profesional de maestros y profesores: el saber práctico o saber hacer, el saber reconstruido en relatos de experiencia, el saber descripto, formalizado y categorizado por la investigación. A tal fin se asumieron dos perspectivas complementarias: la de los docentes y la de los expertos. La primera fue trabajada con docentes que se desempeñan en distintos niveles y modalidades del sistema educativo a partir de entrevistas narrativas y relatos de experiencias.

6 El propósito de esta investigación tuvo que ver con abordar sistemáticamente los modelos, las estructuras, las prácticas y también las trayectorias de los sujetos de distintas y variadas profesiones. Para ello, se consideró la relevancia y el tratamiento que en los campos seleccionados adquieren: la formación práctica, los modos de transmisión del saber hacer, los mecanismos formales e informales de aprendizaje profesional, entre otros. Para ello, fueron utilizados como instrumento los relatos de vida.
Los estudios de este equipo de investigación de la Universidad de Buenos Aires parten de la premisa de que la experiencia siempre está ligada al saber y que es la narrativa la que hace posible dotar de significado a la experiencia. De esta manera, su producción se ha concentrado en la relación entre la experiencia, la narrativa y la construcción del saber pedagógico. En primer lugar, Alliaud (2003) abre el camino con su tesis de doctorado. Ese trabajo estuvo vinculado al estudio del peso de la biografía escolar en el desempeño profesional de los docentes noveles o inexpertos. A partir de allí, se ha inclinado a estudiar las prácticas narrativas vinculadas al "saber de oficio" de pedagogos consagrados (ALLIAUD, 2011). Al reconocer la importancia de asegurar la transmisión del saber hacer en los espacios formales destinados a la formación profesional de los docentes, para que efectivamente maestros y profesores aprendan a enseñar, el trabajo de esta investigadora ofrece caminos alternativos que no suelen recorrerse habitualmente: asegurar el pasaje de los secretos o "gajes" del oficio (ALLIAUD, 2009), disponer de buenas obras de enseñanza, recopilar, coleccionar y tener a mano relatos de experiencias pedagógicas y también generar las condiciones para que éstas se produzcan.

De este modo, Alliaud (2010) liga las narrativas pedagógicas a la posibilidad de avanzar hacia la definición de una pedagogía de la formación con la intencionalidad de aportar ciertas reflexiones que fortalezcan los procesos formativos y los primeros desempeños docentes, a partir de concebir el trabajo docente como una práctica artesanal y como tal, con un modo singular transmisión de esos "saberes del oficio" (ALLIAUD, 2017). Así nos encontramos con docentes contadores de historias, con obras de enseñanza, material fílmico o literario, que intentan generar prác- 
ticas potentes para formar docentes ${ }^{7}$.

Como investigador del mismo equipo, en su línea de investigación Daniel Feldman (2011) se interroga por los procesos de producción de sentido por parte de los docentes. Señala que "cuando los profesores relatan una experiencia de clase, hilvanan diversas imágenes" en forma de metáforas, analogías o escenas. El autor se plantea si las imágenes y relatos son una posibilidad para acceder al conocimiento del que narra o bien son las formas en que el conocimiento está organizado y sostenido. Por su parte, otra de sus integrantes, Lea Vezub, ha explorado la vinculación entre narrativas autobiográficas y trayectorias profesionales docentes. Mediante historias de vida analiza especialmente cuatro dimensiones de las trayectorias: la formación docente inicial, la formación continua junto con otras experiencias formativas, el contexto de acción de los profesores y las prácticas de enseñanza (VEZUB, 2011).

Adriana Fontana (2014), del mismo grupo, ha elegido focalizar su indagación en torno de la pregunta sobre la escuela como lugar posible para la experiencia de la igualdad. Con el propósito de explorar estrategias, acciones y prácticas cotidianas que puedan habilitarla, la investigadora ha adoptado un enfoque de

7 Por otra parte, otros investigadores, preocupados por las didácticas especiales del campo de la lengua y la literatura, también problematizan la cuestión de la escritura en la formación académica y especialmente en el campo de la formación de profesores. Bombini (2015) parte de la idea de la potencia de la escritura en los procesos formativos y de prácticas y resalta la necesidad de explorar en diversidad de géneros de ficción y de no ficción para el abordaje complejo de las prácticas de formación docente, en particular la que tiene lugar en el ámbito universitario. Sus estudios se centran en repensar ciertos estilos de relación con el saber a la hora de planificar las prácticas docentes. Algunas experiencias que ha ensayado con formatos de escritura diferentes de la planificación tradicional advierte acerca de la importancia que tiene la escritura como espacio de anticipación y análisis de las prácticas. Ligado a la productividad de lo narrativo en educación, viene proponiendo desde hace algunos años la escritura de "guiones conjeturales", en tanto que relatos de anticipación, como un género de "didáctica ficción". investigación narrativo. Desde esta perspectiva, ha recurrido a directores de escuelas quienes, a partir de su experiencia, han relatado los modos en que se configuran procesos institucionales y colectivos en torno a la igualdad. Interpretando los relatos, su estudio reconoce que los directores, para hacer lugar a la experiencia de la igualdad en la escuela, en primer lugar realizan una operación de deconstrucción de la gramática escolar y de las reglas tácitas sobre las que se organiza la actividad cotidiana. Luego, o al mismo tiempo, hacen un trabajo político: sostenidos en el oficio de la palabra, buscan construir consenso en torno a prácticas institucionales centradas en la confianza, la responsabilidad y la enseñanza.

A su vez, Gustavo Mórtola (2010) focaliza en los primeros años de inserción laboral, que tienen una potencia formativa de tal magnitud que inscribe saberes y marcas identitarias que acompañarán al docente por un largo tiempo en su vida laboral. Desde una aproximación narrativa a la construcción de la identidad laboral docente, este investigador elige relatos de vida, privilegiando la voz de los docentes (la voz propia de los maestros en la reconstrucción de su sí mismo laboral), y presenta algunas respuestas que atañen a los procesos de aprendizaje docente en esta primera etapa de socialización profesional y también algunos elementos que los docentes rescatan narrativamente en la reconstrucción de sus trayectos laborales (MÓRTOLA, 2006).

\section{Acontecimientos, publicaciones y líneas de investigación (auto) biográficas y narrativas en Mar del Plata: el GIEEC de la UNMdP}

En el contexto argentino, la II Fábrica de Ideas (historias y prácticas) “Narrativas, (auto)biografias y pedagogía: Otra manera de conocer, decir y hacer las experiencias de formación", 
desarrollada en Mar del Plata durante septiembre de 2017, ha sido un hito en términos de consolidar una vinculación sólida y una articulación sistemática entre grupos que despliegan sus investigaciones dentro del campo de la investigación biográfico-narrativa. Ese encuentro de exposiciones orales, lecturas y conversaciones intensas entre grupos de investigación narrativa y (auto)biográfica fue co-organizada por el Grupo de Investigaciones en Educación y Estudios Culturales (GIEEC), coordinado por Luis Porta en el Centro de Investigaciones Multidisciplinarias en Educación (CIMED) de la Facultad de Humanidades de la Universidad Nacional de Mar del Plata (UNMdP), y el grupo de investigación Documentación Narrativa y Memoria Docente en el que participamos los autores de este texto en marco del Instituto de Investigaciones en Ciencias de la Educación de la Facultad de Filosofía y Letras de la Universidad de Buenos Aires.

Si bien desde el año 2013 habíamos tomado conocimiento de este Grupo de Investigaciones a partir de nuestra participación en las VII Jornadas Nacionales sobre la Formación del Profesorado: "Narrativa(s), Práctica(s) e Investigación(es)", que organiza el CIMED bianualmente en la UNMdP y que cuentan con un espacio bien definido dedicado a esta perspectiva de investigación, es la II Fábrica1 de Ideas $^{8}$ el evento que podemos identificar como la ocasión en que algunos de los grupos de investigación más activos del campo narrativo y (auto)biográfico local entramos en contacto y encaramos líneas de trabajo académico cooperativo. Sin dudas, estos acontecimientos

8 Además de investigadores de Argentina, participaron de este encuentro científico investigadores de Chile, Colombia y Brasil. Los paneles principales hicieron foco, entre otros temas, en los desafios metodológicos de la investigación narrativa; en la construcción del 'territorio' de la investigación de corte (auto)biográfica; en el potencial decolonial de las narrativas; en la recursividad y la multiplicidad de interpretaciones en esta clase de investigación; perspectiva; y en una pedagogía de la memoria como campo de investigación biográfico-narrativa en América Latina. científicos y académicos han contribuido a esta articulación, que se ha ido construyendo a partir de una trayectoria nacional e internacional muy fecunda en torno a la investigación biográfica y narrativa de ambos grupos organizadores.

El primero de ellos, el GIEEC de la UNMdP, ha venido desplegando sus trabajos investigativos desde un enfoque culturalista en lo que atañe sobre todo a las historias de vida y a los relatos autobiográficos y testimoniales de "profesores memorables" universitarios, partiendo desde una preocupación pedagógica y didáctica concerniente a la reconstrucción de sus buenas prácticas de enseñanza. Se trata de los sucesivos proyectos de investigación (dirigidos por Luis Porta y co-dirigidos por María Cristina Sarasa) que se mencionan a continuación: "Formación del Profesorado II: La narrativa en la enseñanza" (2006-2007) y "Formación del Profesorado III: (auto) biografias profesionales de los profesores memorables" (20082009). A partir del 2010 el Grupo GIEEC pasa a ser miembro del Centro de Investigaciones Multidisciplinarias en Educación (CIMEd), en el marco del cual se desarrollan los proyectos "Formación del Profesorado IV: biografias de profesores memorables. Vida profesional, mentores y prácticas docentes" (2010-2011) y "Formación del Profesorado V: biografias de profesores memorables. Grandes maestros, Pasiones intelectuales e Identidad profesional" (2012-2013). En el año 2014 el CIMEd pasa a ser un centro asociado al Consejo Latinoamericano de Ciencias Sociales (CLACSO) y la preocupación de los últimos tiempos ha girado en torno de la vinculación de la pedagogía y la didáctica al campo de los estudios poscoloniales. Los proyectos sucesivos fueron: “Formación del Profesorado VI: (auto)biografias y narrativas de instituciones, estudiantes y profesores memorables. Conocimiento, pasiones, emociones y afectos desde una mirada 
decolonial" (2014-2015) y "La construcción de la identidad docente: Trayectorias y relatos de estudiantes y docentes en la formación universitaria" (2016-2017).

A lo largo de estos proyectos, Zelmira Álvarez, Luis Porta y María Cristina Sarasa (2010) se interesaron, entre otras cosas, por explorar los itinerarios de la buena enseñanza a partir de los relatos biográficos docentes como un potente elemento para la formación del profesorado y para la investigación educativa y a resignificar la buena enseñanza desde la voz de docentes memorables en educación superior confrontada, por ejemplo, con Ortega y Gasset y otros académicos (PORTA y SARASA, 2014). A su vez, otra integrante de este equipo, junto con su director, exploraron los desafios ontológicos para la investigación y la enseñanza en la formación de formadores que propicia la investigación biográfico narrativa (PORTA y YEDAIDE, 2014), al tiempo que intentaron revelar su potencia para el alumbramiento de nuevas formas de comprensión de los procesos implicados en la docencia y la investigación en el nivel superior. Estos investigadores proponen la ruptura con la agenda convencional y canónica de la formación de profesores y desafian el estatus de legitimidad conferido a algunos tipos de saberes y sus pretensiones de verdad científica. El trabajo de estos investigadores con profesores y estudiantes en la universidad ha dejado de manifiesto una suerte de currículum paralelo, fuertemente emocional y distintivamente personal y humano, que atraviesa la construcción de las biografías escolares y es altamente pregnante en la configuración de las identidades profesionales. De este modo, el método biográfico-narrativo se presenta como el modo privilegiado de acceso a una sabiduría ubicua e irrefutable que se resiste a alojarse en los textos y las prácticas académicas convencionales.

Desde la Facultad de Arquitectura, Urbanismo y Diseño de la Universidad Nacional de Mar del Plata, María Cristina Martínez articula los proyectos que dirige con el GIEEC, en el marco del CIMED. De esta manera viene investigando la enseñanza proyectual en la arquitectura desde una narrativa "sensible". Martínez y Yedaide (2017) postulan que en el enclave territorial particular de esa disciplina se compone cotidianamente un registro de la práctica de enseñanza del proyecto que presenta un conjunto de trazos materializados, materializables, en parte, mediante abordajes metodológicos propios de la investigación social en general y la investigación narrativa en particular. Por su parte, Claudia de Laurentis (2015) se ha inclinado dentro de este grupo a indagar en la investigación biográfico-narrativa como vehículo para explorar la construcción y la ruptura de identidades en la formación inicial del profesorado. Otra de las investigadoras del GIEEC, Graciela Flores (2012) ha ahondado en su trabajo en la dimensión ética de la pasión por enseñar desde perspectiva biográfico-narrativa en la Educación Superior. Recurrió a la filosofía para revisar sus contribuciones a la investigación biográfico-narrativa en educación y para explicitar perspectivas en torno a la otredad. Laura Proasi (2017), ha explorado un campo singular: la narrativa de la imagen como forma otra en la configuración de la identidad profesional de los alumnos de profesorado desde una mirada decolonial.

Francisco Ramallo, del mismo grupo, ha defendido recientemente una tesis doctoral basada en una investigación narrativa concentrada en los relatos sobre la formación en el bachillerato argentino de la primera mitad del siglo XX, como modo de afirmar la necesidad de indagar y (re)instituir otras historias en la educación (RAMALLO y PORTA, 2017). Por su lado, Jonathan Aguirre problematiza sobre las implicancias emocionales -la propia sensibilidad, los sentimientos- del investigador en la investigación narrativa, particularmente 
en el viaje apasionante que significa el trabajo de campo, y coloca su propia reflexividad en el centro del proceso, replanteando la forma y el modo de producir el conocimiento social (AGUIRRE y PORTA, 2017).

Sin lugar a dudas, el Grupo de Investigaciones en Educación y Estudios Culturales (GIEEC) Facultad de Humanidades de la Universidad Nacional de Mar del Plata ha aportado enormemente a la vigorización del campo de las investigaciones (auto)biográficas en educación en Argentina promoviendo también un conjunto de acontecimientos científicos y académicos de manera sostenida desde el año 2011 y generando una serie de publicaciones específicas muy relevantes de modo sistemático desde el año 2010. Ejemplo de los primeros es el 1er Simposio Internacional La investigación narrativa en educación. Perspectivas y abordajes metodológicos ${ }^{9}$, que el GIEEC organizó conjuntamente con el Centro de Investigaciones Multidisciplinarias en Educación (CIMEd) de la Facultad de Humanidades (UNMdP) en el mes de mayo de 2012. Al año siguiente, en las VI Jornadas Nacionales sobre la Formación del Profesorado: “Currículo, investigación y prácticas en contexto(s)", la perspectiva (auto)biográfica narrativa se hizo presente en dos de sus conferencias centrales y en tres de las mesas de comunicaciones y ponencias. Estas jornadas, que tienen lugar cada dos años en la Universidad de Mar del Plata y son organizadas por el CIMEd, se abocaron de lleno en el 2013 y en el 2015 a este enfoque de investigación en educación ${ }^{10}$.

9 Además de todos los investigadores mencionados, participaron también por el GIEEC Silvia Branda, quien aportó interesantes reflexiones sobre líneas de indagación y contribuciones desde la investigación en torno al interrogante sobre cómo enseñan los buenos docentes, ofreciendo fundamentos y valores que distinguen a las buenas prácticas, y Verónica Ojeda, que se centró en la indagación narrativa y su valor formativo para una pedagogía crítica. Por otra parte, Sonia Bazán, Gladys Cañueto y Gabriela Cadaveira se refirieron al razonamiento y acción pedagógicos a partir de relatos biográficos de profesores principiantes.

10 Muestra de ello es que las VII Jornadas Nacionales sobre
Otro de los eventos importantes que tuvo lugar en Argentina y que fue impulsado por el Grupo que lidera Luis Porta fue el Simposio sobre Investigación Biográfico-Narrativa en el marco del VIII Congreso Iberoamericano de Docencia Universitaria y de Nivel Superior que se llevó a cabo en la Universidad Nacional de Rosario (provincia de Santa Fe) durante los días 21 al 23 de abril de 2014. Además de algunos investigadores del GIEEC (Luis Porta, Zelmira Álvarez, María Marta Yedaide, María Cristina Martínez y Silvia Branda), fue importantísima la presencia de José Ignacio Rivas Flores y Analía Leite Mendez, del Departamento de Didáctica y Organización Escolar de la Facultad de Ciencias de la Educación de la Universidad de Málaga, España, quienes tienen una vasta trayectoria recorrida en este enfoque de investigación en educación. También participó María Teresa Alcalán", de la Universidad del Nordeste Argentina (UNNE), y María Paula Pierella de la Facultad de Humanidades y Artes de la Universidad Nacional de Rosario (UNR), ambas de Argentina ${ }^{12}$. Aunque no como grupo partici-

la Formación del Profesorado llevaron por título "Narrativa(s), Práctica(s) e Investigación(es)" y las VIII "Narración, Investigación y reflexión sobre las prácticas".

11 En su artículo "El sinuoso camino hacia la comprensión del conocimiento docente", Alcalá (2014) nos advierte de que la pluralidad metodológica ha permitido construir universos conceptuales, procesos y prácticas de pensamientos liberados de las restricciones impuestas por el método experimental de las ciencias físico-naturales considerado como único método válido de producción científica. En el camino de la construcción de esta pluralidad metodológica se recuperaron formas de conocer ancestrales de los seres humanos, como es el caso de la narración, del relato, que constituye una creación colectiva de sentidos y significaciones. Según ella, en el campo de la investigación educativa, y más precisamente en el de la didáctica, las narrativas permiten comprender desde perspectivas renovadas los saberes de los docentes. Saberes que generalmente no se escriben y que, sin embargo, componen la sabiduría práctica de la profesión. Saberes, pensamientos, emociones, sentimientos que narrados hacen que nos reconozcamos a nosotros mismos en los otros y, por lo tanto, entender no sólo con la razón, sino también con la experiencia y el corazón.

12 Sin lugar a dudas, en varias universidades más de Argentina vienen desplegándose, con distintos niveles de desarrollo y avances, un número importante 
pante de este simposio, en la UNNE también existe un grupo de investigación que desarrolla actualmente el proyecto denominado "La construcción del conocimiento didáctico del contenido en profesores experimentados y principiantes de la Universidad Nacional del Nordeste. Estudio de casos múltiples". Participan de él, entre otros, Patricia Demuth Mercado, Erika Sánchez y Mara E. Moreyra, y los resultados de investigación son presentados en formato de narrativa, entendida como la mejor estrategia metodológica de presentación de los hallazgos cualitativos y la que permite reflexionar sobre las tramas de vinculación entre el investigador y los sujetos de investigación, y los límites difusos que se generan al emplear estas metodologías.

Muy recientemente, hacia fines de 2017, el GIEEC organizó en la Universidad Nacional de Mar del Plata otro simposio muy sugerente y con una temática muy novedosa. Se trata del “I Simposio sobre Pedagogía Doctoral en Educación. Investigación, relatos y experiencias en la formación doctoral". Sus paneles giraron en torno de las travesías y sentidos vitales y las autobiografías doctorales, de la co-formación de la identidad doctoral y de los aprendizajes biográficos de investigación. Y fue otra oportunidad para la conversación en torno de las experiencias de formación doctoral y para el debate metodológico en base a la narración de experiencias de investigación por parte de

de investigaciones (auto)biográficas y narrativas. Por razones de espacio, y porque eso conllevaría un exhaustivo trabajo de relevamiento que excede los límites de este artículo, sólo mencionaremos algunas de ellas con el riesgo, incluso, de omitir otras. Se trata de aquella que lleva adelante Patricia Gabbarini en la Universidad Nacional de Córdoba; la que realiza José Yuni en la Universidad Nacional de Catamarca; Ivonne Bianco, en la Universidad Nacional de Tucumán, Cristina Nosei, de la Universidad Nacional de La Pampa y otras en la Universidad Nacional de San Luis y en la Universidad Nacional de Salta. Por otra parte, en la misma Universidad de Mar del Plata, María Coria, investigadora del Centro de Letras Hispanoamericanas (CELEHIS), trabaja el entrecruzamiento entre educación, biografía y narrativa. integrantes de los grupos que ya veníamos trabajando en colaboración.

La productiva, intensa y creativa organización de congresos, jornadas, simposios y otros acontecimientos académicos que vienen propiciando el GIEEC son una valiosa y decisiva contribución a la configuración de un campo emergente e incipiente. La persistente sucesión de eventos que disemina el Grupo permite que cada vez más grupos de investigación de universidades nacionales argentinas formen parte de los intercambios y debates del aún impreciso territorio de la investigación biográfico-narrativa en el país. Pero también ha sido considerable su aporte al promover y editar una serie de publicaciones que colaboran a documentarlos, expandirlos y socializarlos. Son la Revista de Educación, que surge en la UNMdP en 2010 (el número 4, de abril de 2012, está íntegramente dedicada a la temática) y la Revista Entramados: educación y sociedad, publicación anual que desde 2014 el GIEEC organiza junto con la Universidad de La Gran Colombia. Lo interesante y auspicioso es que ambas publicaciones son de acceso abierto y gratuito ${ }^{13}$. Por otra parte, el Grupo ha instalado la temática en la formación de posgrado a través del seminario de doctorado "Biografía y Educación: De las teorías a las prácticas investigativas", que se dicta en la Facultad de Humanidades de UNMdP.

\section{Documentación narrativa de experiencias y redes de investigación-formación-acción docente en la Facultad de Filosofía y Letras de la UBA}

El otro grupo de investigación al que referíamos más arriba, que ha venido impulsando

13 Revista de Educación: http://fh.mdp.edu.ar/revistas/ index.php/r educ

Revista Entramados: educación y sociedad: http:// fh.mdp.edu.ar/revistas/index.php/entramados 
una vinculación y una consecuente articulación con otros grupos que despliegan sus investigaciones en la intersección que forman la investigación (auto)biográfica-narrativa y el campo pedagógico en Argentina, es el que dirige uno de los autores de este artículo, Daniel Suárez, en el Instituto de Investigaciones en Ciencias de la Educación de la Facultad de Filosofía y Letras de la Universidad de Buenos Aires, bajo el nombre de Documentación $\mathrm{Na}$ rrativa y Memoria Docente. En este caso, el interés central se relaciona con la posibilidad de desplegar y combinar ciertas prácticas (auto) biográficas y narrativas de experiencia que involucran, indefectiblemente, indagación y producción de saber por parte de los educadores $y$, por lo tanto, instancias sustantivas de trabajo co-participado y experiencias de auto, co y con-formación docente. Tal como lo venimos afirmando en otro trabajos (SUÁREZ, 2014), es este territorio emergente de la investigación-formación-acción docente centrada en la elaboración colectiva y la disposición pública de relatos de experiencias y narraciones autobiográficas, el que viene aportando de modos singulares, diversos y a veces disruptivos al crecimiento, la diversificación y la hibridización de géneros discursivos que caracterizan la expansión del "espacio biográfico" en el campo de la educación del país.

En los últimos quince años en Argentina esa vinculación con otros actores del campo pedagógico en torno de la investigación narrativa y (auto)biográfica tendió a enraizar en las prácticas institucionales de la formación y en las experiencias formativas colectivas. En el caso de este grupo de investigación, los motivos del interés por esta perspectiva de investigación surgieron a partir de constatar los límites metodológicos y político-pedagógicos que evidenció la "teoría del déficit" en formación docente luego del desmoronamiento de la reforma educativa neoliberal y tecnocrática de la década de los noventa en Argentina (Suárez, 2003). El discurso reformista responsabilizaba a los docentes por la crisis educativa y el "vaciamiento de conocimientos en las escuelas" $y$, por tanto, fueron objeto de múltiples intervenciones desde el campo especializado de la educación. La solución reformista al problema se orientó a suministrar recursos y estrategias técnicas que reemplazaran los rudimentarios saberes de los docentes, impregnados de creencias y prejuicios, por la certeza, mensurabilidad y predicción del saber especializado, experto y científico-técnico. Los efectos de este discurso azuzaron la desacreditación del sector docente y la descalificación de su posición en el campo pedagógico y el consecuente silenciamiento o desdén de sus voces y la negación de las palabras que utilizaban para dar cuenta de la educación que practican, reflexionan e indagan de forma cotidiana y al ras de sus experiencias pedagógicas.

Como la contracara de este movimiento y su discurso, comenzó a gestarse una importante resistencia del sector docente y de una parte importante del campo pedagógico crítico a esa reforma. Por ello, las palabras, la experiencia vivida en el mundo escolar y los saberes pedagógicos construidos y reconstruidos en torno de ella por los docentes, cobraron un nuevo valor y una importante centralidad en el escenario político educativo (SUÁREZ, 2005). Este reconocimiento público y la visibilización de los "saberes de oficio" recreados en recorridos locales y singulares fueron los que permitieron la revalorización pedagógica de los sujetos de la formación docente.

Lo que queremos enfatizar es que desde hace ya algún tiempo, cada vez más proyectos y políticas educativas nacionales, provinciales y locales de Argentina estuvieron incorporando y articulando estrategias narrativas, (auto) biográficas y formativas, y también que desde los sindicatos docentes y organizaciones y mo- 
vimientos político-pedagógicos se impulsaron proyectos que articularon elaboración de relatos de experiencia, desarrollo profesional y militancia educativa y social. Una parte importante de estos procesos colectivos de producción (auto)biográfica, de formación mediante la indagación narrativa de la propia práctica y de intervención pedagógica colectiva han sido coordinados por este grupo mediante procesos de investigación-formación-acción docente a través de la documentación narrativa de experiencias pedagógicas. Muchos de estos proyectos están presentados y problematizados en profundidad en algunos trabajos de Daniel Suárez (2009 y 2012). Por eso aquí nos limitaremos, por razones de espacio, a hacer una muy sintética descripción de solo algunos de ellos.

Entre el año 2004 y 2005, el proyecto “Estrategias y materiales pedagógicos para la retención escolar", puesto en marcha desde el Ministerio de Educación, Ciencia y Tecnología de la Nación y la Agencia Interamericana para la Cooperación y el Desarrollo de la Organización de Estados Americanos (OEA), y del que fuimos convidados a participar como formadores de directivos y docentes que llevaban adelante prácticas inclusivas en sus escuelas, nos permitió sistematizar en documentos escritos y manuales muchos de los saberes que habíamos venido construyendo en la experiencia de impulsar proyectos de documentación narrativa como estrategia de formación docente y como medio para la reconstrucción de la memoria y el saber pedagógico. También por aquellos años fuimos invitados por el Consejo Provincial de Educación de la Provincia de Santa Cruz a coordinar procesos de documentación narrativa de experiencias de desarrollo curricular en el marco del Programa “Educación de Calidad y con Equidad de aquella provincia de la Patagonia argentina. Por el mismo tiempo, un colectivo de docentes de Jardines de Infantes Comunitarios de la Ciudad Autónoma de Buenos Aires, documentaba sus experiencias en estas peculiares instituciones que atendian a la primera infancia por fuera de la red escolar oficial. Uno de sus resultados fue la publicación de un relato colectivo que mostraba otras formas de ser docentes ${ }^{14}$.

En los años 2007 y 2008, bajo condiciones políticas e institucionales reguladas por el Instituto Nacional de Formación Docente (INFD) del Ministerio de Educación, Ciencia y Tecnología (MECyT), nuestro equipo formó alrededor de 200 coordinadores de los Centros de Actualización e Innovación Educativa (CAIEs) como coordinadores de procesos de documentación narrativa, que se desplegaron territorialmente en quince provincias de Argentina. Este proyecto, que se llamó "Documentación narrativa de experiencias y viajes pedagógicos", implicó una importante movilización de actores y recursos políticos y pedagógicos ${ }^{15}$ y en su marco hemos desarrollado una cantidad interesante de materiales pedagógicos centrados en la documentación de la experiencia escolar mediante relatos de experiencia y autobiográficos ${ }^{16}$.

Entre los años 2008 y 2010, una serie de proyectos nos tuvieron experimentando meto-

14 Se trató del Proyecto "Fortalecimiento del carácter educativo de Jardines de Infantes Comunitarios a través de la inclusión de docentes". Dirección General de Planeamiento. Secretaría de Educación. Gobierno de la Ciudad Autónoma de Buenos Aires. Y la publicación se llamó "Otra forma de ser maestros. Una experiencia de inclusión de docentes en Jardines de Infantes Comunitarios de la ciudad de Buenos Aires".

15 Este proceso implicó viajes, encuentros presenciales y virtuales, debates, intercambios, disputas y acontecimientos político-pedagógicos experienciados por casi mil quinientos docentes a lo largo de Argentina.

16 Entre otros podemos mencionar a Suárez, D. H. ¿Qué es la Documentación Narrativa de Experiencias Pedagógicas? (Fascículo 2) y Suárez, D. H.; Ochoa, L.; y Dávila, P. ¿Cómo escribir relatos pedagógicos? Orientaciones y ejercicios para la práctica de escritura de relatos pedagógicos. (Fascículo 4) de la Colección de Materiales Pedagógicos Documentación Narrativa de Experiencias y Viajes Pedagógicos. Instituto Nacional de Formación Docente del Ministerio de Educación, Ciencia y Tecnología de la Nación y Laboratorio de Políticas Públicas de Buenos Aires. Buenos Aires, 2007. 
dológicamente el dispositivo de la documentación narrativa en torno de experiencias pedagógicas que acontecen en espacios singulares o poco explorados por la investigación educativa convencional. En el marco de una investigación para el Centro de Cooperación Regional para la Educación de Adultos en América Latina y el Caribe (CREFAL), un buen número de docentes que despliegan sus tareas en contextos de encierro plantearon, a través de la producción de relatos, el campo de tensiones para la inclusión educativa que se juega en esos ámbitos (SUÁREZ, FREJTMAN, DÁVILA y BUSTELO, 2012). Al mismo tiempo, mediante la puesta en marcha del dispositivo de investigación-formación-acción, tanto docentes de educación secundaria como instructores de formación técnico-profesional indagaron narrativamente -y de eso modo problematizaron- la articulación entre ambos espacios educativos cuando se conjugan para formar para la inclusión (EYHARCHET; SUÁREZ; DÁVILA, 2012).

Otro de los procesos de investigación-formación-acción docente fue el desarrollado en los años 2011 y 2012 desde la Universidad Pedagógica de la Provincia de Buenos Aires (UNIPE) junto con las direcciones Provincial de Nivel Inicial y de Investigación Educativa de la provincia de Buenos Aires $Y$ fue documentado en profundidad y dispuesto públicamente en Suárez, Argnani. Dávila, Galli (2015) ${ }^{17}$

17 Se trató de los proyectos "Relatos de experiencia, docentes y prácticas pedagógicas en el nivel inicial: Reconstrucción narrativa y autobiográfica de experiencias docentes de La Matanza, San Martín y Pilar" y "Memoria pedagógica e innovación educativa en el nivel inicial. Documentación narrativa de experiencias de innovación pedagógica en redes de investigación-formación-acción entre docentes". Todo fue documentado y dispuesto públicamente en una serie de materiales pedagógicos y documentos narrativos. Luego de eso, pero ya desde la Universidad de Buenos Aires, aún seguimos profundizando este trabajo pero exclusivamente en el territorio de La Matanza, primero a través de un proyecto co-participado con la jefatura regional de educación número 3 de la provincia de Buenos Aires y luego desde los coordinadores de esa región que conformaron varios colectivos de docentes narradores.
Lo interesante de estos proyectos es que, además de conseguir que los docentes se conviertan en investigadores narrativos y (auto) biográficos de sus propias experiencias, al mismo tiempo, se posicionan como sujetos de su propia formación y desarrollo profesional ${ }^{18}$. Y esto a su vez ha impulsado la incorporación de las prácticas (auto)biográficas y narrativas en las prácticas institucionales cotidianas de las escuelas.

Otro de los proyectos fue el desarrollado en el año 2013 junto con el Instituto Rosita Ziperovich de la Asociación del Magisterio de Santa Fe (AMSAFE-CTERA) ${ }^{19}$, y logró conformar un colectivo de docentes santafecinos que co-investigan narrativa y (auto) biográficamente sus prácticas pedagógicas en la escuela y el sindicato a partir de la elaboración de relatos de experiencias. En esta ocasión, lo que resultó singular fue la revitalización de zonas de contacto bien interesantes "entre la investigación educativa académica, la formación sindical y pedagógica de los docentes, las políticas de conocimiento y reconocimiento en el campo pedagógico y las prácticas narrativas y autobiográficas que llevan adelante los sujetos desde distintas posiciones de enunciación y de discurso" (SUÁREZ, 2014, p. 775).

El año 2016 fue auspicioso para el trabajo de formación, investigación y extensión que veníamos desarrollando como dimensiones imbricadas de nuestro trabajo en la Facultad de Filosofía y Letras de la Universidad de Bue-

18 Y no sólo eso. También se posicionan como docentes autores de documentos pedagógicos. Así lo demuestran, por ejemplo, los cuatro volúmenes de relatos de experiencias que se publicaron desde La Matanza desde el 2012 al 2015.

19 El proyecto se llamó “Memoria pedagógica y sindical docente en la Provincia de Santa Fe. Documentación narrativa de experiencias pedagógicas en redes de investigación-formación-acción entre docentes". y el sindicato docente quiso desarrollarlo como parte de las actividades que desarrollarían en el marco del Movimiento Pedagógico Latinoamericano que viene impulsando la Internacional de la Educación (IE) desde fines del año 2011. 
nos Aires desde la perspectiva (auto)biográfica: por primera vez poníamos en marcha desde el Programa de Extensión la Diplomatura en Desarrollo Profesional Docente centrado en la Investigación-Acción de la Práctica y lo desplegábamos en el Municipio de San Fernando, en el conurbano norte de la provincia de Buenos Aires. Esta propuesta, que se desarrolló en 10 meses, se llevó adelante en tres momentos formativos -articulados entre sí- mediante estrategias (auto)biográficas y narrativas como metodología principal de intercambio y fortalecimiento del desarrollo profesional ${ }^{20}$. En 2017 la Diplomatura tuvo una nueva edición. Esta vez, para que un colectivo de directores de Centros de Formación Técnico-Profesional de la Ciudad de Buenos Aires documente narrativamente, tematice, problematice y conceptualice sus experiencias de conducción y gestión de esas instituciones educativas singulares ${ }^{21}$.

A lo largo de variados proyectos de investigación-formación-acción como estos hemos podido concluir que, al invitar a los docentes a la reconstrucción de la propia palabra, de la propia experiencia y de la memoria escolar, estas iniciativas ha logrado tensionar los modos en que se diseñaban y desarrollaban las políticas públicas en materia de currículum, evaluación, formación y capacitación docente, y se han apartado fuertemente de las propuestas desautorizantes de las políticas educativas tecnocráticas que mencionábamos más arriba y a las que pretendemos combatir y rechazar. Por el contrario, se fundan como espacios y

20 Estos tres momentos son: el Taller Documentación narrativa de prácticas docentes y experiencias pedagógicas; el Seminario Elementos teóricos y metodológicos de la investigación-formación-acción docente y el Laboratorio de Tematización, problematización y conceptualización de las experiencias pedagógicas. Los coordinadores de nuestro equipo a cargo de estas distintas instancias fueron: Daniel Suárez, Paula Dávila, Agustina Argnani, Cecilia Tanoni, Gladys Zarenchansky y Marina Spiridonov.

21 Esta vez, la articulación para el despliegue de la Diplomatura fue con el Observatorio de la Educación y el Trabajo de la Fundación Unión de Obreros de la Construcción de la República Argentina (ODET-FUOCRA). tiempos de experimentación metodológica y política para el reconocimiento de los géneros (auto)biográficos y narrativos en la investigación educativa, en las prácticas escolares, en las políticas educativas y en la formación docente, al tiempo que legitima a los docentes como sujetos de investigación y de producción de conocimiento en el campo de la formación docente y de la investigación educativa. En otras palabras, se tornan indispensables para la visibilización de prácticas de formación que se apoyan en la producción, la lectura, los comentarios y la conversación en torno de materiales biográfico-narrativos y que, hasta no mucho tiempo tiempo, eran parte de las tácticas secretas de los formadores de formadores, pero no se documentaba públicamente. $Y$ también, la experimentación metodológica en torno de la investigación biográfico-narrativa que se ha dado en el marco de los proyectos aquí reseñados, los convierte en referencia ineludible para reconocer y legitimar a los docentes no sólo como sujetos de formación mediantes estrategias biográfico-narrativas sino -y fundamentalmente para los propósitos de este artículo- como sujetos y no como objetos de investigación educativa y de discurso pedagógico con poder de intervención pública y especializada en el "campo conceptual" de la educación (ZULUAGA y ECHEVERRI, 2003). Un nuevo territorio de revitalización y recreación del discurso y de la praxis pedagógica, en el que se puedan generar conversaciones y debates que confluyan en formas más colectivas de producción, circulación, recepción y publicación del saber y el conocimiento educativo. Ejemplo de ello es el crecimiento y la expansión en Argentina de una importante cantidad y heterogeneidad de redes pedagógicas de docentes y educadores, muchas de las cuales ponen en el centro de sus preocupaciones a la investigación docente desde variados y disímiles enfoques. 
Nos referimos a las diez redes nacionales que conforman lo que ellas mismas han dado en llamar el Colectivo Argentino de Docentes que hacen Investigación desde la Escuela22. Se trata de dinámicas configuraciones de sujetos, experiencias, saberes pedagógicos que se afianzan crecientemente como modos de organización alternativos, pero que definen reglas de composición y criterios de validación propios. Estas modalidades poco convencionales de organización político-pedagógica apelan al trabajo co-participado de docentes, formadores, educadores populares, investigadores universitarios. Si bien muchas de ellas surgieron al calor de la resistencia a las políticas tecnocráticas impulsadas por las reformas educativas neoliberales luego adquirieron una orientación propositiva y transformadora y se constituyeron en usinas de producción de saberes pedagógicos, de auto y co-formación de docentes.

Como parte de las redes que conforman el Colectivo Argentino hay una que se aloja específicamente en la intersección o concurrencia entre narrativa, (auto)biografía y formación (SUÁREZ y ARGNANI, 2011). Se trata de la Red de Formación Docente y Narrativa Pedagógicas, que estimulamos y desarrollamos desde el año 2010 desde un Programa de Extensión Universitaria de la Facultad de Filosofia y Letras de la Universidad de Buenos Aires, y que se articula con nuestras tareas de investigación (y de docencia) que de manera integral desarrollamos desde allí. Esta red articula colectivos de docentes que llevan adelante procesos de indagación narrativa y autobiográfica de sus propias experiencias. Los nodos de la Red componen formas descentradas de organización social para la producción y divulgación de

22 El Colectivo Argentino participa a su vez de la Red Iberoamericana de Colectivos y Redes de Maestros y Maestras que hacen Investigación e Innovación desde la Escuela y la Comunidad, en la que se congregan redes de España, Argentina, Colombia, Venezuela, México, Perú y Brasil. saberes pedagógicos a través de la publicación y circulación de relatos de experiencias producidos por los propios docentes. $Y$ se erige en un espacio horizontal de reflexión, investigación y de formación que combina instancias de trabajo colectivas e individuales. Tiene el propósito de problematizar y recrear el lenguaje y el pensamiento pedagógicos en virtud de la construcción y reconstrucción narrativa y autobiográfica de la experiencia escolar, su sistematización, publicación, difusión y deliberación pública $y$, en ese movimiento, tornar autores a los educadores de narrativas que dan cuenta de experiencias y saberes pedagógicos que los tienen como protagonistas y promueven el propio desarrollo profesional a través de la conversación y la (re)significación colectiva de lo experimentado, reconstruido y documentado (SUÁREZ, 2008).

Como puede verse, en el desarrollo de los proyectos de investigación de los que venimos siendo parte, la formación en investigación (auto)biográfica y narrativa de tesistas y becarios se conjuga con proyectos de desarrollo profesional docente a través del despliegue de acciones de extensión universitaria que articula la Red. Este espacio de investigación, formación e intervención en red en el campo pedagógico facilitó además que el director, los investigadores, los becarios y los tesistas de este equipo de investigación vengamos organizando una sucesión constante de eventos científicos nacionales e internacionales especializados que ofician de un magnífico plafón para que sus integrantes interaccionemos con otros grupos que hacen investigación (auto) biográfica y narrativa en educación de la región y del mundo ${ }^{23}$.

23 Algunos de ellos fueron nuestros persistentes Seminarios Internacionales Itinerantes por los nodos de la Red de Formación Docente y Narrativas Pedagógicas, que el Grupo organiza y desarrolla desde el año 2008. Solo por nombrar algunos: Seminario Internacional Itinerante "Formación, Narrativas y Redes Pedagógicas" (2012) y Seminario Itinerante "Narrativas, Formación Docente e Investigación Educativa" (2011). Otros 
Estos auténticos encuentros de construcción colectiva de conocimientos han sido además la usina que permitió generar publicaciones que se convirtieron en verdaderas intervenciones discursivas, y que han permitido instalar y consolidar a la investigación (auto) biográfica y narrativa en el campo pedagógico en Argentina ${ }^{24}$. Tal es el caso de la colección de libros iniciada en 2009 "Narrativas, autobiografias y educación"25, que coeditan la Facul-

han sido simposios, coloquios, jornadas, foros. Todos ellos han sido fundamentales para empezar a trabajar en redes de cooperación científica, de manera constante y tenaz con investigadores de universidades de otros países de América Latina y Europa, fundamentalmente de Brasil (universidades Federal do Rio Grande do Norte; con las de los Estados de Bahía (UNEB); con las Federal do Estado de Río de Janeiro y UNIRIO; y con la Universidad Comunitaria de Caxias do Sul); de Francia (Universidad de Paris 13 y Universidad Francois Rabelais, Tours); de México (universidades Pedagógica Nacional y Nacional Autónoma de México); de Colombia (Universidad de Antioquia); de Chile (Universidad de Chile) y de España (Universitat de Barcelona y Universitat Ramón Llull, Blanquerna; de Portugal (Universidad de Coimbra), entre otros. Como efecto de esos armados institucionales, en el año 2010 conformamos la Red Latinoamericana de Narrativas, Autobiografias y Educación (Red NAUE) y, en 2013, la Red científica de investigación biográfica en educación América latina-Europa (Red BioGrafia), en donde comparten saberes relacionados con diferentes experiencias de indagación en los diversos territorios y a través de distintas estrategias metodológicas.

24 También han aportado a la instalación de la perspectiva autobiográfica y narrativa en el Programa de Doctorado del área de Educación de la Universidad de Buenos Aires, los seminarios que ha dictado en ese marco Daniel Suárez en 2015 y en 2017, respectivamente: "Investigación educativa, formación docente y relatos de experiencia. La documentación narrativa de experiencias pedagógicas como estrategia de investigación-formación-acción docente" y "Experiencia, narrativa y (auto) biografia en la formación docente y la investigación educativa". Y en 2018, el que desarrolla en la Universidad Nacional de La Plata, "Experiencia, narrativa y (auto)biografía en la investigación educativa".

25 La colección es dirigida por Daniel Suárez, y se edita en articulación con colecciones homólogas coordinadas en Francia y Brasil por Christine Delory-Momberger, Elizeu Clementino de Souza y Maria da Conceiçao Passeggi. Hasta el momento cuenta con cuatro volúmenes publicados: Biografía y educación. Figuras del individuo-proyecto, de Christine Delory Momberger (2009); Memoria docente, investigación y formación, organizado por Elizeu Clementino de Souza y Maria Conceicao Passeggi (2010); El saber de la experiencia. Narrativa, investigación y formación docente (2011), compilado por Andrea Alliaud y Daniel Suárez; Narra- tad de Filosofía y Letras de la Universidad de Buenos Aires y el Consejo Latinoamericano de Ciencias Sociales, y que sin dudas es un material vital para la circulación de esta perspectiva y de las ideas y proyectos que se generan en torno de ella. Pues si bien venían circulando cada vez más artículos de investigadores narrativos y (auto)biográficos en congresos y revistas, la ausencia de publicaciones especializadas y monográficas sobre estas temáticas venía constituyendo un obstáculo para la generación, actualización y socialización del conocimiento vinculado con estas modalidades de investigación en la Argentina.

Como decíamos, venía habiendo en nuestro equipo de investigación una intensa producción en torno de estas cuestiones llevada adelante por su director, sus investigadores, becarios y tesistas para la definición y la discusión de nuevos problemas teórico metodológicos que reclamaban su visibilización y proyección a través de eventos académicos como de publicaciones científicas. Por ello, queremos ahora dar cuenta breve e imperfectamente de esa producción que, si bien de autoría individual, no deja de ser por completo colectiva. Sin dudas, la prolífica producción intelectual que el grupo venía desarrollando desde inicios de este siglo en torno de la investigación biográfico narrativa tiene una primera oportunidad de ser condensada en la tesis de doctorado de Daniel Suárez, "Relatos pedagógicos, docentes e investigación narrativa de la experiencia escolar. Aportes de la investigación cualitativa y colaborativa para la formación y el desarrollo profesional de los docentes", finalizada en el año 2009. Tomándola como punto de referencia ineludible, el trabajo de todo su equipo comienza a expandirse y ramificarse. Bajo su orientación, Paula Dávila, en su tesis de maes-

tivas de experiencia en educación y pedagogía de la memoria (2015), compilado por Gabriel Jaime Murillo; y dos nuevos volumenes se encuentran en pleno proceso de edición. 
tría "Escribir e interpretar la experiencia: la documentación narrativa de prácticas pedagógicas", se preocupó por estudiar uno de los momentos clave de dicho dispositivo, el de edición pedagógica, y así explorar sus potencialidades en tanto espacio de reconocimiento de otros escenarios y actores como lugares y sujetos de producción de saberes pedagógicos (DÁVILA, 2014). Más específicamente, ha podido examinar las estrategias para la lectura interpretativa y comentada y la reescritura de relatos pedagógicos escritos por docentes que tienen lugar en procesos de documentación narrativa de experiencias pedagógicas y ha podido analizar las potencialidades de esas estrategias para el despliegue de procesos reflexivos y formativos entre colegas, en colectivos conformados ${ }^{26}$ (DÁVILA, 2017).

Por su parte, Agustina Argnani se propuso, también en el marco de su tesis de maestría “Redes pedagógicas, relatos de experiencias y formación docente. La Red de Formación Docente y Narrativas Pedagógicas, un estudio en caso", investigar los procesos de producción de saber pedagógico y las modalidades de formación docente que tienen lugar en el marco de colectivos y redes de docentes autores y lectores de relatos pedagógicos. Su tesis indaga, particularmente, los procesos de disposición pública de documentos narrativos escritos por los docentes y de su circulación en ámbitos especializados (ARGNANI, 2014). Esto es, la publicación y circulación como dos momentos específicos del dispositivo de documentación narrativa que resultan centrales en los procesos de investigación-formación-acción que ese dispositivo se propone desplegar ${ }^{27}$. Cabe men-

26 Actualmente continúa profundizando en este sentido en la tesis de doctorado que se encuentra desarrollando "Estrategias biográfico-narrativas en educación para el desarrollo profesional de docentes".

27 Esta investigadora está desarrollando un nuevo trabajo como doctoranda en el que se interesa por prácticas y propuestas impulsadas por docentes formadores (de la formación docente inicial) que sostienen la producción de conocimientos pedagógicos como cionar que la singularidad que reúne el trabajo de estos tres investigadores reside en que en ellos se explora, examina, analiza y reflexiona metodológicamente un dispositivo de investigación-formación-acción docente inspirado en la investigación (auto)biográfica y narrativa en educación.

No obstante, dentro del mismo equipo de la Universidad de Buenos Aires hay otras investigadoras que se dedican a estudiar diversos ámbitos educativos a través de estrategias (auto)biográficas y narrativas. Tal es el caso de Danise Granjeiro Godim (2014), cuya tesis de doctorado "La sabiduría profesional: las historias de vida de los profesores jubilados" indaga sobre el papel que el saber experiencial ocupa dentro de la formación de profesores. A través de la producción de relatos de trayectoria pedagógica de docentes jubilados, su investigación buscó definir la sabiduría profesional y de este modo escribir e inscribir los discursos de los docentes jubilados, antes silenciados y no documentados. También el de Cynthia Bustelo, quien en su tesis "Experiencias educativas en contextos de encierro: un abordaje pedagógico desde la perspectiva narrativa y (auto) biográfica", aborda los espacios y tiempos educativos en contextos de encierro a través de la (re)construcción de historias de vida de personas que transitaron algún tipo de experiencia de formación en la cárcel. A partir de los escritos de sí, explora experiencias significativas en situación de encierro que hayan dado lugar a algún dislocamiento en la biografia educativa, provocando cambios de posición subjetiva (Bustelo, 2015). Por su lado, en distintos trabajos Yanina Caressa estudia los modos en que las comunidades de aprendizaje profesional centradas en la producción

parte constitutiva de la formación a través de la implementación de dispositivos de enseñanza apoyados en los principios teórico-metodológicos de la investigación (auto)biográfica y narrativa en educación (Argnani, en prensa). 
de saber pedagógico contribuyen a redefinir las posiciones y disposiciones de supervisores/inspectores dentro del aparato burocrático escolar y cómo éstas entran en tensión y/o articulación con las establecidas y legitimadas por el sistema escolar. Y lo hace a través de la puesta en marcha de un proceso de documentación narrativa (CARESSA, 2017). Otra de las integrantes de este equipo de investigación, María Eugenia Míguez, pretende analizar (en una tesis que desarrolla actualmente) de qué manera un Plan de finalización de estudios secundarios (FINEs) contribuye a la construcción de experiencias educativas en los jóvenes y adultos. Para ello, su trabajo se vuelca a la reconstrucción -a través de historias de vida- de las trayectorias educativas de los estudiantes para de comprender cómo tienen lugar estas configuraciones de lo educativo en contextos de desigualdades y diferencias sociales, culturales y educativas (CARESSA y MíGUEZ, 2016). A su vez, en sus diversos trabajos Gabriel Roizman utiliza el dispositivo de documentación narrativa de experiencias pedagógicas tanto como para explorar en lo que concierne a madres y padres adolescentes y sus experiencias educativas (2012) como a la educación matemática con jóvenes y adultos o a la alfabetización inicial de infantes.

\section{Una cartografía todavía imperfecta}

El trazado del mapa que dé cuenta de manera exhaustiva del incipiente campo de la investigación (auto)biográfica y narrativa en Argentina está todavía en construcción. Y tal vez siempre lo esté. Este artículo ha sido solo un intento de cartografía todavía muy vinculado a nuestra bitácora de experiencias, a nuestro propio recorrido y búsqueda. Son notaciones de nuestra propia perspectiva del territorio, de nuestra propia participación y orientación en él, que disponemos bajo la forma de ensayo para la elaboración de un mapa colectivo. Otras miradas, escrituras y trazados podrán aportar a su permanente recreación y también a la conformación del propio campo. La creciente activación de las redes de intercambio, asociación y colaboración entre grupos; el reconocimiento recíproco y el encuentro solidario y horizontal de investigadores, tesistas, becarios, estudiantes y docentes en diferentes espacios y momentos de conversación; la multiplicación de publicaciones conjuntas que den cuenta de la diversidad de perspectivas y experiencias de investigación; y la generación y difusión de opciones de posgrado centradas en la investigación narrativa y (auto)biográfica, pueden ser también oportunidades para que los contornos del territorio se traduzcan en mapa.

La expansión del "espacio biográfico" hacia el campo educativo en Argentina resulta evidente: la presencia de estrategias y herramientas metodológicas narrativas y (auto)biográficas en la investigación educativa, la formación de docentes y las prácticas escolares está siendo documentada y debatida, y ha logrado cierta legitimidad. Pero la delimitación de un campo local específicamente centrado en el desarrollo, debate y profundización de la investigación narrativa y (auto)biográfica en educación aún requiere de relatos, notas y bosquejos que muestren e informen perspectivas y experiencias en él. Las potencialidades de sus estrategias para impulsar procesos de construcción coparticipada o colaborativa de conocimientos sobre la experiencia pedagógica y el mundo escolar; para promover procesos y experiencias de auto, co y con-formación y desarrollo profesional docente; y para intervenir discursivamente en el campo de disputas por el sentido de lo pedagógico, requieren ser desplegadas, discutidas, profundizadas. La tarea de construir colaborativamente el mapa y 
de configurar el campo son las dos caras de la misma moneda.

\section{Referencias}

ALCALÁ, María. El sinuoso camino hacia la comprensión del conocimiento docente. Revista de Educación, Universidad Nacional de Mar del Plata, n. 7, p. 93-102, 2014.

AGUIRRE, Jonathan; PORTA, Luis. Narrativas de una política pública innovadora en formación docente. Los "polos de desarrollo" desde las voces y relatos de los sujetos. En: FÁBRICA DE IDEAS - Historia y prácticas. Narrativas (Auto)biografias y Pedagogía: otra manera de conocer, decir y hacer las experiencias de formación, 2., 2017, Mar del Plata. Anais eletrônicos... Mar del Plata: CIMEd; Universidad Nacional de Mar del Plata, 2017. Disponible en: <http:// fh.mdp.edu.ar/encuentros/index.php/fabricadeideas/2fi2017/schedConf/presentations. Aceso en: 4 abr. 2018.

ARGNANI, Agustina. Redes pedagógicas, relatos de experiencias y formación docente. La Red de Formación Docente y Narrativas Pedagógicas, un estudio en caso. 2014. 184 f. Tesis (Maestría en Pedagogías críticas y problemáticas socioeducativas) - Facultad de Filosofia y Letras, Universidad de Buenos Aires, Buenos Aires, 2014.

ARGNANI, Agustina. Aportes del enfoque (auto)biográfico-narrativo en educación a la formación inicial de docentes: dispositivos y estrategias para la investigación de la propia práctica. En: ORCE, Victoria. (Comp.). La educación como espacio de disputa. Miradas y experiencias de los/las investigadores/as en formación. Buenos Aires: EFFyL, en prensa.

ALLIAUD, Andrea. La biografía escolar en el desempeño escolar de los docentes noveles. 2004. $292 \mathrm{f}$. Tesis (Doctorado en Educación) - Facultad de Filosofia y Letras, Universidad de Buenos Aires, Buenos Aires, 2004.

ALLIAUD, Andrea. Experiencia, narración y formación docente. Educação \& Realidade, Porto Alegre, Universidade Federal do Rio Grande do Sul, v. 31, n. 1, p. 7-22, enero/jun. 2006.
ALLIAUD, Andrea. Los artesanos de la enseñanza. Acerca de la formación de maestros con oficio. Buenos Aires: Paidós, 2017.

ÁlVAREZ, Zelmira; PORTA, Luis; SARASA, María C. Itinerarios de la buena enseñanza a partir de los relatos biográficos docentes. Profesorado: revista de curriculum y formación del profesorado, Granada, Universidad de Granada, v. 14, n. 3, p. 89-98, 2010.

BATALLÁN, Graciela. Docentes de infancia. Antropología del trabajo en la escuela primaria. Buenos Aires: Paidós, 2007.

BOMBINI, Gustavo. Prácticas de formación docente y escritura de ficción. Cuadernos de Educación, Córdoba, Universidad Nacional de Córdoba, v. 13, n. 13, mayo 2015.

BUSTELO, Cynthia. Experiencias de formación transformación en contextos de encierro. Un abordaje político-pedagógico desde la perspectiva narrativa y (auto)biográfica. En: JORNADAS DE JÓVENES INVESTIGADORES, 8., 2015, Buenos Aires. Anais... Buenos Aires: Instituto de Investigaciones Gino Germani; Universidad de Buenos Aires, 2015. p. 122-134.

CARESSA, Yanina. Experiencias de supervisión en un proceso de investigación-formación-acción docente. Un estudio en caso en La Matanza, Provincia de Buenos Aires. En: ORCE, Victoria. (Comp.). La educación como espacio de disputa. Miradas y experiencias de los/las investigadores/as en formación. Buenos Aires: EFFyL, en prensa.

CARESSA, Yanina; MIGUEZ, María Eugenia. Reconstruyendo otros modos de conocer y construir conocimiento: reflexiones en torno a la investigación (auto)biográfica y narrativa en educación. En: ENCUENTRO LATINOAMERICANO DE METODOLOGÍA DE LAS CIENCIAS SOCIALES (ELMeCS) - Métodos, metodologías y nuevas epistemologías en las ciencias sociales: desafios para el conocimiento profundo de nuestra América, 5., 2016, Mendoza. Anais eletrônicos... Mendoza: Facultad de Ciencias Políticas y Sociales, Universidad Nacional de Cuyo, 2016. Disponible en: <http://www.memoria.fahce.unlp.edu. ar/trab eventos/ev.8507/ev.8507.pdf>. Aceso en: 6 jun. 2018. 
CARLI, Sandra. Deconstruir la profesión académica: tendencias globales y figuras históricas. Una exploración de las biografias académicas de profesoras universitarias. Propuesta Educativa, Buenos Aires, año 25, v. 1, n. 45, p. 81-90, jun. 2016.

DÁVILA, Paula. Escribir e interpretar la experiencia: la documentación narrativa de prácticas pedagógicas. 2014. 183 f. Tesis (Maestría en Educación, pedagogías críticas y problemáticas socioeducativas) - Facultad de Filosofia y Letras, Universidad de Buenos Aires, Buenos Aires, 2014.

DÁVILA, Paula. Indagar la experiencia: la formación y la reflexión pedagógica en el proceso de producción de relatos de docentes. En: FÁBRICA DE IDEAS - Historia y prácticas. Narrativas (Auto)biografias y Pedagogía: otra manera de conocer, decir y hacer las experiencias de formación, 2., 2017, Mar del Plata. Anais eletrônicos... Mar del Plata: CIMEd; Universidad Nacional de Mar del Plata. Disponible en: <http://fh.mdp.edu.ar/encuentros/index.php/ fabricadeideas/2fi2017/schedConf/presentations>. Aceso en: 7 mar. 2018.

DE LAURENTIS, Claudia. Identidad docente: herramientas para una aproximación narrativa. Revista Entramados - Educación y Sociedad, Mar del Plata, UNMdP, año 2, n. 2, p. 67-74, sept. 2015.

EYHARCHET, Carlos; SUÁREZ, Daniel; DÁVILA, Paula. (Coords.). Articulando historias y vivencias: relatos de educadores de articulación formación profesional y educación secundaria. Buenos Aires: Aulas y Andamios, 2012.

FELDMAN, Daniel. Imágenes en los relatos sobre la experiencia docente. En: ALLIAUD, Andrea; SUÁREZ, Daniel. (Orgs.). El saber de la experiencia: narrativa, investigación y formación docente. Buenos Aires: Facultad de Filosofía y Letras de la Universidad de Buenos Aires (EFFyL); Consejo Latinoamericano de Ciencias Sociales (CLACSO), 2011. p. 100-113.

FLORES, Graciela. La dimensión ética de la pasión por enseñar: una perspectiva biográfico-narrativa en la educación superior. Praxis Educativa, v. 16, n. 2, p. 52-61, jul./dic. 2012.

FONTANA, Adriana. La construcción de la igualdad en la escuela desde la perspectiva de los directores: análisis y narrativa de tres casos. 2014. $156 \mathrm{f}$. Tesis (Maestría en Diseño y gestión de políticas y programas sociales) - Faculdad Latinoamericana de Ciencias Sociales (FLACSO), Buenos Aires, 2014.

GRANGEIRO GODIM, Danise. La sabiduría profesional: las historias de vida de los profesores jubilados. 2014. 276 f. Tesis (Doctorado en Educación) Faculdad de Filosofia y Letras Universidad de Buenos Aires, 2014.

HERMIDA, Carola; PIONETTI, Marinela; SEGRETIN, Claudia. Formación docente y narración: una mirada etnográfica de las prácticas. Buenos Aires: Noveduc, 2017.

LLOSA, Sandra. Biografias educativas de adultos de sectores populares: algunos desafios metodológicos. En: CONFERENCIA INTERNACIONAL DE SOCIOLOGÍA DE LA EDUCACIÓN, 2004, Buenos Aires. Anais... Buenos Aires, 2004.

LLOSA, Sandra. La perspectiva biográfica en educación. Reflexiones acerca de los desafíos de la combinación del abordaje cualitativo con instancias participativas. En: ENCUENTRO LATINOAMERICANO DE METOdología dE LAS CIENCIAS SOCIALES, 5., 2016, Mendoza. Anais eletrônicos... Mendoza: Universidad Nacional de La Plata, Facultad de Humanidades y Ciencias de la Educación. Centro Interdisciplinario de Metodología de las Ciencias Sociales, 2016. Disponible en: <http://fh.mdp.edu.ar/encuentros/index.php/fabricadeideas/2fi2017/schedConf/ presentations>. Aceso en: 10 jun. 2018.

MARTÍNEZ, María; YEDAIDE, María. Una narrativa sensible de la enseñanza proyectual. En: FÁBRICA DE IDEAS - Historia y prácticas. Narrativas (Auto) biografias y Pedagogía: otra manera de conocer, decir y hacer las experiencias de formación, 2., 2017, Mar del Plata. Anais eletrônicos... Mar del Plata: $\mathrm{Cl}-$ MEd; Universidad Nacional de Mar del Plata, 2017. Disponible en: <http://fh.mdp.edu.ar/encuentros/ index.php/fabricadeideas/2fi2017/schedConf/presentations>.Aceso en: 3 mayo 2018.

MÓRTOLA, Gustavo. Una aproximación narrativa a la construcción de la identidad laboral docente: algunos aspectos biográficos previos a la formación 
inicial. Educación, Lenguaje y Sociedad, v. 4, n. 4, p. 83-104, dic. 2006.

MÓRTOLA, Gustavo. Enseñar es un trabajo: construcción y cambio de la identidad laboral docente. Buenos Aires: Noveduc, 2010.

PIERELLA, María. Acerca de la autoridad en narrativas de estudiantes universitarios: algunos avances de un proyecto de investigación en curso. Conexión, Revista de Investigaciones y Propuestas Educativas, n. 28, p. 107-126, 2010.

PIERELLA, María. Itinerarios biográficos de jóvenes estudiantes. La Universidad pública como espacio de experiencias culturales. Estudio sobre juventudes en Argentina. En: AA.VV. Líneas prioritarias de investigación en el área jóvenes/juventud: la importancia del conocimiento situado. Salta: Red de Investigadora/es en Juventudes de Argentina y Editorial de la Universidad Nacional de Salta. 2012. p. 315-333.

PIERELLA, María. Universidad, conocimiento y transmisión: un estudio centrado en biografias de profesores de carreras humanísticas y científicas. Revista d'Innovació i Recerca en Educació, v. 8, p. 31-49, 2015.

PORTA, Luis; SARASA, María Cristina. Resignificar la buena enseñanza desde la voz de docentes memorables en educación superior confrontada con Ortega y Gasset y otros académicos. Profesorado, v. 18, n. 1, p. 293-306, enero 2014.

PORTA, Luis; YEDAIDE, María Marta. La investigación biográfico narrativa: desafios ontológicos para la investigación y la enseñanza en la formación de formadores. Sophia, Universidad Politécnica Salesiana, n. 17, p. 177-192, 2014.

PROASI, Laura. La narrativa de la imagen como forma otra en la configuración de la identidad profesional de los alumnxs del profesorado. En: FÁBRICA DE IDEAS - Historia y prácticas. Narrativas (Auto) biografias y Pedagogía: otra manera de conocer, decir y hacer las experiencias de formación, 2., 2017, Mar del Plata. Anais eletrônicos... Mar del Plata: $\mathrm{Cl}-$ MEd; Universidad Nacional de Mar del Plata, 2017. Disponible en: <http://fh.mdp.edu.ar/encuentros/
index.php/fabricadeideas/2fi2017/schedConf/presentations>. Aceso en: 8 jun. 2018.

RAMALLO, Francisco; PORTA, Luis. Una investigación narrativa sobre el bachillerato argentino. En: FÁBRICA DE IDEAS - Historia y prácticas. Narrativas (Auto) biografias y Pedagogía: otra manera de conocer, decir y hacer las experiencias de formación, 2., 2017, Mar del Plata. Anais eletrônicos... Mar del Plata: $\mathrm{Cl}-$ MEd; Universidad Nacional de Mar del Plata, 2017. Disponible en: <http://fh.mdp.edu.ar/encuentros/ index.php/fabricadeideas/2fi2017/schedConf/presentations >. Aceso en: 8 jun. 2018.

ROIZMAN, Gabriel. Documentación narrativa de experiencias pedagógicas en los límites de la salud sexual. En: AA.VV. Embarazo, maternidad y paternidad adolescentes. Buenos Aires: Ed. CICCUS, 2012. p. 220-235.

SUÁREZ, Daniel. Dispersión curricular, descalificación docente y medición de lo obvio. Los efectos pedagógicos de la reforma educativa de los ‘ 90 '. Novedades Educativas, Buenos Aires-México, año 15, n. 155, p. 44-49, nov. 2003.

SUÁREZ, Daniel. Reforma del Estado, protesta social y conflicto docente en Argentina: un caso para el estudio de la conflictividad educativa en América Latina. Serie Ensayos \& Investigaciones, Buenos Aires, Laboratorio de Políticas Públicas, n. 5, p. 231283, 2005.

SUÁREZ, Daniel. Docentes, narrativa e investigación educativa: la documentación narrativa de las prácticas docentes y la indagación pedagógica del mundo y las experiencias escolares. En: SVERDLICK, I. (Comp.). La investigación educativa. Una herramienta de conocimiento y acción. Buenos Aires: Novedades Educativas, 2007. p. 71-110.

SUÁREZ, Daniel. Orígenes, desarrollo y proyección de la documentación narrativa de experiencias pedagógicas en Argentina. Boletín de noticias sobre educación, Buenos Aires, Fundación Luminis, año 1, n. 7, nov. 2008. Disponible en: <https://www.fundacionluminis.org.ar/>. Aceso en: 16 dic. 2017.

SUÁREZ, Daniel. Relatos pedagógicos, docentes e investigación narrativa de la experiencia escolar. 
Aportes de la investigación cualitativa y colaborativa para la formación y el desarrollo profesional de los docentes. 2009. $412 \mathrm{f}$. Tesis (Doctorado en Educación) - Faculdad de Filosofía y Letras, Universidad de Buenos Aires, Buenos Aires, 2009.

SUÁREZ, Daniel. Narrativas, autobiografias y formación en Argentina. Investigación, formación y acción entre docentes. En: SOUZA, Elizeu; BRAGANÇA, Inês. (Orgs.). Memória, dimensões socio-históricas e trajetórias de vida. Natal: EdiPUCS; Porto Alegre: EDUFRG; Salvador: EDUNEB, 2012. p. 57-94.

SUÁREZ, Daniel. Espacio (auto)biográfico, investigación educativa y formación docente en Argentina: un mapa imperfecto de un territorio en expansión. Revista Mexicana de Investigación Educativa, v. 19, n. 62, p. 763-786, jul./sept. 2014.

SUÁREZ, Daniel; ARGNANI, Agustina. Nuevas formas de organización colectiva y producción de saber pedagógico. La Red de Formación Docente y Narrativas Pedagógicas. Educação e Contemporaneidade, Salvador, FAEEBA, v. 20, n. 36, p. 43-56, jul./dic. 2011.

SUÁREZ, Daniel; ARGNANI, Agustina; DÁVILA, Paula; GALLI, María. Reconstrucción narrativa y autobiográfica de experiencias docentes en el nivel inicial. En: PEREYRA, Ana et al. Prácticas pedagógicas y políticas educativas. Investigaciones en el territorio bonaerense. Gonnet: UNIPE, 2015. p. 283-310.

SUÁREZ, Daniel; DÁVILA, Paula. (Comps.). Más allá del oficio. Relatos docentes de formación profesional. Buenos Aires: Aulas y Andamios, 2009.
SUÁREZ, Daniel; DÁVILA, Paula. Documentación narrativa de experiencias pedagógicas. Una modalidad de investigación interpretativa y una estrategia de formación de maestros. En: SOUZA, Elizeu. (Org.). Educação e ruralidades. Memórias e narrativas (auto)biográficas. Salvador: EDUFBA, 2012. p. 353-377.

SUÁREZ, D.; FREJTMAN, V.; DÁVILA, P.; BUSTELO, C. Entre la escuela y la cárcel: campo de tensiones para la inclusión educativa. Informe Final de Investigación. Apoyo a Proyectos de Investigación de Centro de Cooperación Regional para la Educación de Adultos en América Latina y el Caribe (CREFAL). Buenos Aires: Instituto de Investigaciones en Ciencias de la Educación; Facultad de Filosofía y Letras; Universidad de Buenos Aires, 2012.

VEZUB, Lea. ¿Qué cuentan las trayectorias de desarrollo profesional de los docentes sobre su oficio? En: ALLIAUD, Andrea; SUÁREZ, Daniel. (Orgs.). El saber de la experiencia. Narrativa, investigación y formación docente. Buenos Aires: Facultad de Filosofia y Letras de la Universidad de Buenos Aires (EFFyL); Consejo Latinoamericano de Ciencias Sociales (CLACSO), 2011. p. 114-142.

ZULUAGA, Olga; ECHEVERRI, Alberto. Campo intelectual de la educación y campo pedagógico: posibilidades, complementos y diferencias. Pedagogía y Epistemologia, Bogotá, Cooperativa Editorial Magisterio y Grupo de la Práctica Pedagógica, Pedagogía e Historia, n. 1, p. 111-126, 2003.

Recebido em: 15.06 .2018 Aprovado em: 20.08.2018

Daniel Hugo Suárez Doctor en Ciencias de la Educación por la Universidad de Buenos Aires, Instituto de Investigaciones en Ciencias de la Educación (IICE) y Departamento de Ciencias de la Educación, Facultad de Filosofía y Letras, Universidad de Buenos Aires. Profesor Titular Regular a cargo de la Materia Problemas Pedagógicos Contemporáneos (Ciclo de Formación General) / Educación II - Análisis de los sistemas de educación formal y no formal, y del Seminario Problemas y corrientes contemporáneas de teoría de la educación I. "Pedagogías críticas, experiencias de la praxis y movimientos pedagógicos en América Latina" (Seminario Obligatorio del Ciclo de Formación Focalizada: Teorías de la Educación). Grupo de Pesquisa Documentación Narrativa y Memoria Docente del Instituto de Investigaciones en Ciencias de la Educación de la Facultad de Filosofia y Letras de la Universidad de Buenos Aires. Director del Proyecto de Investigación "Discursos, sujetos y prácticas en la conformación del campo pedagógico. Sentidos y disputas contemporáneas en torno del conocimiento educativo, la formación y el trabajo docentes y las desigualdades educativas" (Programación UBACyT 2018-2020). e-mail: danielhugosuarez@gmail.com

Calle Púan 480, 4to piso, Oficina 428, C.P: 1406, Ciudad Autónoma de Buenos Aires (CABA), Argentina. Teléfono: 5411 5287-2870 ó $54115287-2869$ 
Paula Valeria Dávila Magister en Educación de la Universidad de Buenos Aires. Maestría en Educación "Pedagogías críticas y problemáticas socio-educativas". Facultad de Filosofia y Letras de la Universidad de Buenos Aires. Instituto de Investigaciones en Ciencias de la Educación (IICE) y Departamento de Ciencias de la Educación, Facultad de Filosofía y Letras, Universidad de Buenos Aires. Investigadora Tesista del Proyecto de Investigación “Discursos, sujetos y prácticas en la conformación del campo pedagógico. Sentidos y disputas contemporáneas en torno del conocimiento educativo, la formación y el trabajo docentes y las desigualdades educativas" (Programación UBACyT 2018-2020). Jefa de Trabajo Prácticos de la Materia Problemas Pedagógicos Contemporáneos (Ciclo de Formación General) / Educación II - Análisis de los sistemas de educación formal y no formal, y Profesora Adjunta del Seminario Problemas y corrientes contemporáneas de teoría de la educación l. "Pedagogías críticas, experiencias de la praxis y movimientos pedagógicos en América Latina" (Seminario Obligatorio del Ciclo de Formación Focalizada: Teorías de la Educación). Grupo de Pesquisa Documentación Narrativa y Memoria Docente del Instituto de Investigaciones en Ciencias de la Educación de la Facultad de Filosofía y Letras de la Universidad de Buenos Aires. e-mail: paulavdavila@gmail.com

Calle Púan 480, 4to piso, Oficina 428, C.P: 1406, Ciudad Autónoma de Buenos Aires (CABA), Argentina. Teléfono: 5411 5287-2870 ó 5411 5287-2869 